\title{
CABRAL, Rui Pires. A Super-Realidade. Lisboa: Língua Morta, 2011 . 40 p.
}

Julia Telésforo Osório

Universidade Federal de Santa Catarina

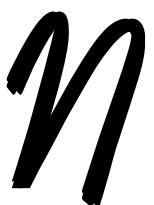

o final de 2011, a editora portuguesa Língua Morta publicou um curioso livro assinado por Rui Pires Cabral, autor que vem se destacando no cenário literário português nos últimos quinze anos, especialmente a partir de Música Antológica E Onze cidades (Presença, 2007), muito repercutido pela crítica de poesia contemporânea de autores como Rosa Maria Martelo, Joaquim Manuel Magalhães, Pedro Eiras, Gastão Cruz etc. A Super-Realidade, título homônimo ao do segundo livro do poeta, já era um objeto conhecido entre seus leitores desde os anos 90. Logo na abertura, encontra aquele que lê essa edição uma espécie de aviso, uma nota de autor: "Este livro é uma reedição. Emendei alguns versos, rasurei outros tantos e excluí nove dos trinta e cinco poemas que compunham a versão original, publicada em Vila Real no outono de 1995".

Trata-se, obviamente, de uma reedição. De um livro (re)lido e (re)escrito pelo autor que, depois de 1995, publicou outros sete livros de poesia e teve poemas selecionados para compor muitas antologias literárias com destaque para a tão comentada Poetas sem qualidades (Averno, 2002), organizada por Manuel de Freitas. Na nova versão de $A$ Super-Realidade, alguns detalhes editoriais podem ajudar a compreender seu significado na obra in progress

${ }^{1}$ CABRAL, 2011, p. 3. 
de Rui Pires Cabral. Foram impressos, apenas, cem exemplares, todos assinados pelo poeta a caneta esferográfica azul. Cada exemplar é singular, possui uma espécie de marca, um número que lhe é próprio numa série até cem. O número por mim lido é o "98", também numerado pela mesma tinta azul que o autografa. Agora, compõem esse livro vinte e seis poemas. Não há mais a presença de um índice no final do livro com a nomeação de todos esses poemas, ao contrário da "versão original" e também dos demais livros de poesia publicados, além das alterações feitas na linguagem poética da maioria dos poemas quando comparados aos do livro de 1995. Evidências de uma intervenção consciente de Rui Pires Cabral nesta nova $A$ Super-Realidade, materializada, sobretudo, na voz confessa em primeira pessoa da já citada "Nota de autor", que parece querer justificar as páginas seguintes.

Diante disso, acredito serem pertinentes alguns questionamentos: faz-se necessária a escrita de uma nota autoral a fim de justificar a publicação de determinado livro, mesmo que ele seja uma reedição? Seria "legitimada" a leitura desses vinte e seis poemas somente porque eles foram reeditados, revisados e remendados? Suas versões anteriores seriam, nesse sentido, "descartáveis", e não deveriam, portanto, serem lidas sem a devida comparação com essas novas versões apresentadas ao leitor? Por qual motivo, enfim, se reeditou A Super-Realidade se, aparentemente, esses versos são reescrituras, versões "melhoradas"?

Quatro poemas presentes na primeira edição "Velocidade", "Night Clubbing", "Super-Realidade" e "Esplanada" - foram selecionados para o segundo volume da antologia brasileira Portugal, 0, dedicada à obra de Rui Pires Cabral. Feitas as comparações entre as duas versões de cada poema, nota-se, apenas, uma alteração. Em "Super-Realidade", uma mudança de termos que, à primeira vista, pode parecer 
insignificante, mas que amplia o trabalho com a sonoridade / o/ no poema, que "ecoa" durante a leitura do segundo verso e se contrapõe à sonoridade /a/ do termo "baço", destacando e isolando-a na posição de sílaba tônica característica de final de verso, que rima com a do verso anterior e com outras, conforme os grifos em itálico:

Eu era de terra quando me procuraste, estranho à fraqueza dos teus modos [na primeira versão, "actos"], baço para os teus sentidos.

Parávamos o carro num beco qualquer, queimávamos o rastilho das palavras até ao deserto onde dávamos as mãos.

Lá fora, a realidade era o espaço inteiro deitado nos vidros, o mundo caído para dentro do silêncio.

Gastávamos depressa o tempo, perdidos no nosso único mapa, nenhum sinal de mudança no regresso a casa. ${ }^{2}$

Além da troca de termos (substantivos, adjetivos e verbos, mas também preposições, expressões adverbiais, etc.), outras mudanças são percebidas como aquelas relativas a minuciosas revisões de ortografia, de pontuação e de grafia de letras como, por exemplo, o uso de maiúsculas e minúsculas e a escolha pela escrita de números por extenso ou em algarismos. Mesmo que em menor frequência, destacam-se, entretanto, as mudanças estruturais decorrentes da reescritura ou do apagamento de partes de versos e estrofes e novos rearranjos estruturais na disposição sintática de termos ao longo dos versos.

${ }^{2}$ CABRAL, 2011, p. 33. Grifos meus. 
Muitas dessas alterações foram realizadas em "Hospital Cantonal de Perreux", ocasionando uma diferença substancial no que diz respeito à acentuação do viés narrativo desse poema, cujo sujeito poético parece relembrar um episódio de viagem, se comparado à sua primeira versão. $\mathrm{O}$ uso do tempo verbal imperfeito contribui, decisivamente, para o efeito de uma memória em movimento que se constrói ao longo do texto. Trata-se de um recurso que favorece uma dinâmica "contínua" e é reforçado pelos acentuados trabalhos com as sonoridades /i/ e /p/, que se repetem no poema, sendo esta última evidenciada pela escolha de termos que causam um efeito de aliteração da consoante /p/ em diálogo com o nome do lugar, Perreux, na França:

Aqueles jardins tinham o gosto da anestesia no céu da boca, havia longas alamedas poluídas pelo segredo dos pavilhões proibidos [interditos].

Os internados [pensionistas] dormiam toda a tarde sem ruído,

às seis [6] vinham a tropeçar pelo refeitório, cumprimentavam no seu francês turvado pelos químicos: Ça va, m'sieur [grifos do autor]? Eu andava à procura de um acelerador

para a minha viagem, interrogava constantemente os meus oráculos, o livro aberto sobre as sombras no terraço.

Eram mesmo para mim as mensagens que encontrei [Algumas cidades tiveram mensagens] nos muros de algumas cidades, ou foram só ilusões [escritas nos seus muros para mim, ou eram só as ilusões] engendradas pelo acaso? Eu não sabia responder naquela altura, tal como nunca soube. Às vezes o silencio de Perreux era confortável para os meus sentidos, trazia-me depressa 
o sono. Na manhã seguinte, eu voltaria a partir [eu partiria outra vez]. ${ }^{3}$

Curioso pensar que o tema da viagem já abordado nesse livro continuou a ser desenvolvido posteriormente na obra de Rui Pires Cabral, especialmente nos livros Longe da aldeia (Averno, 2005), em que muitos poemas se referem a uma viagem à Inglaterra e ao retorno a Portugal, e Capitais da solidão (Teatro Vila Real, 2006), em que se leem diversas referências a cidades europeias como Paris, Budapeste, Lisboa, Barcelona e Birmingham. Também outros temas continuam recorrentes desde $A$ Super-realidade, tais como: o amor e a desilusão, trabalhados constantemente em referência explícita a um "tu"; a mobilidade nas geografias das grandes cidades através da representação de espaços públicos e privados; as menções a elementos da cultura contemporânea e, também, à literatura. No penúltimo livro publicado, Oráculos de cabeceira (Averno, 2009), os títulos de cada poema reme a trechos de livros referenciados por notas de rodapé, cujas referências bibliográficas encontram-se ao final do livro, antes do "Índice", numa seção intitulada "Abertos ao acaso". Desde 2009, portanto, leem-se fortes sinais que evidenciam, na poesia de Rui Pires Cabral, a consciência de um projeto poético.

Das notas de rodapé remetentes a cânones literários à reescritura e respectiva publicação do seu segundo livro, há, de fato, uma preocupação estética, um amadurecimento do trabalho poético. Nesse sentido, a segunda versão d'A Super-Realidade pode ser lida como um testemunho, uma forma de acompanhar essa obra in progress, assim como a sua consciência artesanal, tão cara a qualquer discurso poético. Como dito por Pedro Eiras, um destacado crítico da recente poesia portuguesa, o poema é ficção verbal, um trabalho da língua, resultante de um labor, ${ }^{4}$ e a poesia

${ }^{3}$ CABRAL, 2011, p. 10. Grifos meus.

${ }^{4}$ EIRAS, 2011, p. 48. 
continua a ser experiência com a linguagem, mesmo que agora esteja ela mergulhada numa contemporaneidade, num tempo sem qualidades, materializada em obras de autores que usam e abusam de versos livres e prosaísmos, como é o caso de Rui Pires Cabral.

Assim, o gesto de reescritura d'A Super-Realidade, mais do que concretizar um possível desejo de remendo de versos ou poemas inteiros, pode ser compreendido como uma maneira de ler essa obra. A nova versão do segundo livro não substitui a primeira, ao contrário: problematiza ainda mais aquela publicada em 1995. E a sua "Nota de autor" testemunha algo já tão questionado pelos estudos literários: a importância da voz do autor para a compreensão de sua obra. Mesmo que ele declare que o livro de 2011 consiste numa versão melhorada do seu segundo livro, aquelas primeiras versões dos poemas ainda estão lá para serem lidas e comparadas com as que agora se apresentam. Comparar as duas versões de cada poema é um ato interessante por vários motivos, mas destaco a importância desse gesto para entender como a obra e, sobretudo, a linguagem poética se desenvolvem, pois estão em progresso, sendo construídas a cada dia, independentemente de Rui Pires Cabral ser um declarado leitor crítico de si mesmo. Como dizem seus versos, ainda é preciso "continuar a meter o coração/ pelos atalhos" que tanto podem ser as publicações de poemas inéditos ou reescritos.

\section{Referências}

CABRAL, Rui Pires. A Super-Realidade. Vila Real: Edição do autor, 1995. CABRAL, Rui Pires. A Super-Realidade. Lisboa: Língua Morta, 2011. CABRAL, Rui Pires. Poemas. In: MAFFEI, Luis (Org.). Portugal, 0. v. 2. Rio de Janeiro: Oficina Raquel, 2007.

EIRAS, Pedro. Um certo pudor tardio: ensaio sobre os "poetas sem qualidades". Porto: Edições Afrontamento, 2011. 